\title{
Sobre apariencia y realidad en Aristóteles. La interpretación de Marcelo Boeri
}

\author{
JoRge MitTELMANN \\ Instituto de Filosofía \\ Universidad de los Andes (Chile) \\ jmittelmann@uandes.cl
}

\begin{abstract}
Resumen: En su reciente libro sobre las nociones de apariencia y realidad en el pensamiento antiguo, Marcelo Boeri ofrece un análisis detallado del papel que Aristóteles atribuye a las apariencias tanto en las apreciaciones cognitivas como en las morales. A la luz del tratamiento paralelo que Boeri reserva al error en contextos morales y epistémicos, aquí se desarrollan algunas sugerencias suyas que parecen apuntar hacia una incipiente "criteriología" aristotélica. Tal como el virtuoso provee el "canon y medida" de las apariencias moralmente fiables, el adecuado entrenamiento (y el ejercicio conjunto) de las facultades de discriminación sensorial e intelectual provee garantías suficientes sobre la fiabilidad de las apariencias sensibles. Cierra este trabajo un breve examen de las estrategias de "disolución" que Aristóteles adopta ante el escepticismo perceptivo.
\end{abstract}

Palabras clave: percepción, error, criterio, escepticismo

\begin{abstract}
In his recent work on the concepts of appearance and reality in ancient Greek thought, Marcelo Boeri offers a detailed account of the role Aristotle assigns to the phantasiai, both in our moral and cognitive assessments. In the light of this somewhat unitary account of moral and epistemic mistakes, this paper takes further some of Boeri's suggestions, which seem to point in the direction of an inchoate Aristotelian "criteriology". The virtuous person provides the "canon and measurement" of the morally trustworthy appearances; in much the same way, the joint exercise (and suitable training) of our sensory and intellectual discriminatory abilities assures the reliability of perceptible appearances. A brief account of the Aristotelian "dissolution strategy" against radical skepticism closes this paper.
\end{abstract}

Key words: perception, error, criterion, skepticism

Marcelo Boeri consagra dos capítulos de su libro Apariencia y realidad en el pensamiento griego (en adelante $A R$ ) a discutir el alcance de esta distinción en la psicología y en la teoría de la acción de Aristóteles. Su acercamiento a la cuestión reviste algunos rasgos distintivos que justifican un examen detenido. Como era previsible, Boeri se interna en el problema que da título al libro mediante una detallada reconstrucción del concepto aristotélico de $\varphi \alpha \nu \tau \alpha \sigma i \alpha$, tanto en su vertiente epistémica como práctica. La fantasía es el orden de "lo que aparece" o "se presenta", pero es también el orden de "lo que me parece" como resultado de 
ese aparecer, o quizá incluso al tomar distancia de él ( $A R$, p. 228). Aris-

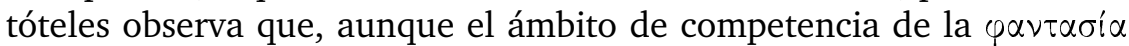
parece ser coextensivo al de la sensación, calificamos como $\varphi \alpha \nu \tau \alpha \sigma i ́ \alpha$ (y no como "sensaciones") aquellos "apareceres" de cuyo valor cognitivo no estamos ciertos (428a12-16). Por lo demás, piensa Aristóteles, la Q $\alpha \nu \tau \alpha \sigma i \alpha$ resulta errónea en la mayor parte de los casos (428a12).

En su análisis de esta facultad, Boeri alude en más de una ocasión a la presencia (al menos implícita) de modos de discriminar entre la fiabilidad de dos apariencias contrapuestas, al punto de afirmar que "Aristóteles puede haber visualizado un criterio del cual nosotros todavía disponemos cuando hacemos la distinción apariencia-realidad" ( $A R$, p. 230). Si bien Boeri nunca explicita del todo cuál es el criterio último de rectitud presupuesto por Aristóteles en nuestras discriminaciones perceptivas, la doble orientación teórico-práctica de su análisis de la $\varphi \alpha \nu \tau \alpha \sigma i \alpha$ provee importantes indicios al respecto. En esta discusión intentaremos explotar el tratamiento paralelo que Boeri reserva a las distinciones entre bien real y aparente (por un lado) e impresiones veraces y erróneas (por el otro) a efectos de precisar ese criterio al que Aristóteles recurre; o (en palabras de Boeri) de aclarar cuáles son "[sus] maneras de decidir la 'realidad' que torna verdaderas nuestras creencias" ( $A R$, p. 229). En primer término se discutirán las consideraciones que el autor ofrece en torno de la discriminación entre apariencias contrapuestas, para examinar, en un segundo momento, la estrategia general que Aristóteles diseña para hacer frente al desafío escéptico. ${ }^{1}$

\section{Aristóteles y el criterio de verdad}

Un supuesto básico que atraviesa el texto de Boeri es que la distinción entre lo aparente y lo real no es estrechamente epistémica, ni su discusión interviene sólo en contextos vinculados con la justificación del conocimiento. La compenetración de lo epistémico y lo ético está insinuada ya en el subtítulo del libro, y quizá no sea aventurado sugerir

${ }^{1}$ Aunque los problemas de "criteriología" en sentido estricto ocuparán el centro del debate filosófico recién en el período helenístico, ciertamente cabe decir con Barnes 1987, p. 53, que las dificultades en cuestión "ya habían despuntado por el horizonte en tiempos de Aristóteles". Como observa M.R. Stopper (1983, p. 266), en Metafísica $\Gamma$, Aristóteles discute una serie de argumentos "que más tarde reaparecen con casi la misma forma en los diez modos de los pirrónicos. Las coincidencias son considerables: indujeron a Aristocles a afirmar que Aristóteles había refutado la filosofía de Pirrón antes de que éste la elaborara." Para este último testimonio Stopper remite a Eusebio, Praeparatio Evangelica XVIII, 2.

Diánoia, vol. LIV, no. 63 (noviembre 2009). 
que los contextos en los que inicialmente surge esa distinción -o en los que al menos se vuelve apremiante la necesidad de introducirla-, son contextos de filosofía práctica. En tales contextos, un agente ofuscado por lo que se le presenta como bueno es incapaz de sustraerse "al poder

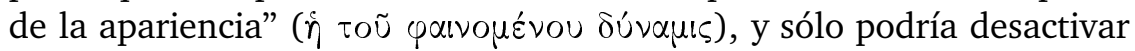
ese poder "poniendo en perspectiva" lo que le aparece, mediante la aplicación de cierto "arte de la medida" ( $\dot{\eta} \mu \varepsilon \tau p \eta \tau i x \grave{\eta} \tau \varepsilon \dot{\varepsilon} \chi \nu \eta$ : cfr. Protágoras, 356d4). El arte de la medida permitirá relativizar lo inmediatamente apetecible e interponer tiempo entre el deseo y su satisfacción, al abrir un intervalo en el que lo placentero ya no se presente "como placentero en sentido estricto, es decir como un bien en sentido estricto", porque entre tanto el agente habrá incorporado "el futuro" en su apreciación de lo presente. ${ }^{2}$ El que la distinción entre apariencia y realidad resulte crítica en contextos de racionalidad práctica, sumado a la relevancia que el factor temporal reviste en la discriminación entre lo aparente y lo real, pone de relieve que dicha distinción tiene un valor no sólo epistémico, sino también dramático. De ella depende, al menos en parte, el que la vida del agente resulte lograda o se malogre, y no sólo la justificación del estatus epistémico de sus creencias, articuladas en proposiciones que pretenden describir el mundo.

Habida cuenta de esta ambivalencia en la distinción entre apariencia y realidad, Boeri procura mantener abierta la circulación entre la ofuscación del agente racional y sus percepciones erróneas, e intenta alinear los errores elementales de discriminación perceptiva con la parcialidad de sus juicios prácticos. Aunque esa estrategia no logra eliminar un núcleo de apariencias confusas que se presentan incluso al observador imparcial y bien predispuesto, sí permite mostrar la índole práctica de cierto número de distorsiones perceptivas. Además, contribuye a definir gradualmente cierto "canon y medida", esto es, un sujeto de experiencia cuyas impresiones sensibles (como, en otro plano, las del virtuoso) coincidan indefectiblemente con la realidad. ${ }^{3}$

${ }^{2}$ Me sirvo aquí libremente de la traducción de Marcelo Boeri para De Anima III 10, 433a22-b11, texto en el que Aristóteles parece dialogar activamente con Platón, Protágoras 356d3-e2. Aristóteles tiene presente las ideas de Platón en su propia caracterización del conflicto motivacional entre deseos de corto plazo y deseos racionales de largo plazo, que incorporan lo futuro en el cálculo o planificación ( $\lambda o \gamma\llcorner\sigma \mu o ́ \varsigma)$ de la praxis. Boeri discierne también ese trasfondo en las líneas conclusivas de Ethica Nicomachea III 4 (1113a29-b2): cfr. AR, pp. 184; 180-182.

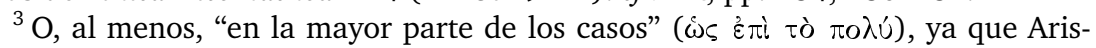
tóteles admite que la sensación de los sensibles propios podría estar contaminada

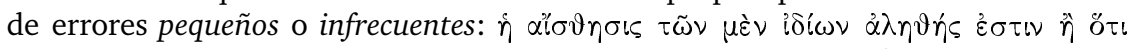

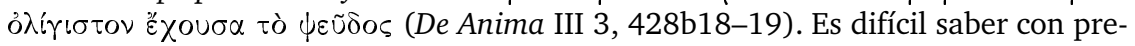


El punto de partida que adopta Boeri se hace patente en lo que podríamos llamar (quizá abusivamente) su genealogía moral del error perceptivo. Buena parte de nuestros juicios erróneos proviene de una desordenada interferencia emocional en la evaluación de "lo que se presenta" por vía senso-perceptiva: "Aristóteles piensa que los sentidos no nos engañan, sino que son nuestros estados afectivos los que nos hacen interpretar falsamente los datos de los sentidos" ( $A R$, p. 230).

No se trata, claro está, de que Boeri reduzca todos los reportes sensoriales potencialmente desorientadores a una interpretación defectuosa de datos fiables, por parte de agentes ofuscados en la prosecución de un bien aparente. Sin embargo, parece evidente su reticencia a encarar el problema de la fiabilidad de esos reportes en términos exclusivamente gnoseológicos. Resulta llamativo que, apremiado por la tarea de precisar en detalle cuál es el criterio que Aristóteles "podría haber visualizado" y "del cual todavía disponemos al hacer la distinción apariencia-realidad" ( $A R$, p. 230), el autor imprima a su discusión un marcado sesgo hacia la filosofía práctica. Lo avala en este tránsito de lo epistémico a lo ético un significativo pasaje del tratado Sobre los sueños (460b3-27), en el que Aristóteles ilustra, mediante varios ejemplos, la tesis según la cual "nos equivocamos fácilmente en lo que respecta a nuestras senso-percepciones cuando estamos sumidos en un

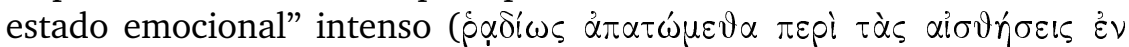

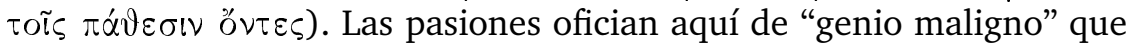
nos induce en un perspectivismo cuasi cartesiano: tal como a quienes emprenden una travesía marítima les parece que el paisaje se desplaza ante sus ojos, sin advertir que lo que se desplaza es su mirada, ${ }^{4}$ así también, cuando nuestra receptividad sensible se halla bajo el influjo de un estado emotivo, articulamos juicios falsos sobre "lo que se presenta". ${ }^{5}$

Sin duda es preciso introducir aquí un matiz, pues, como observa Jonathan Barnes, "en todos estos casos el error afecta a objetos incidentales de percepción y es respecto de ellos que las pasiones inducen

cisión si el adverbio sugiere una presencia esporádica o ínfima de falsedad en la aprehensión de los sensibles propios. (Agradezco esta precisión a Jonathan Barnes.)

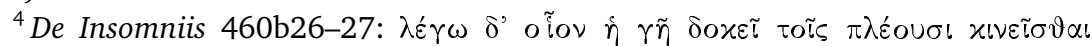

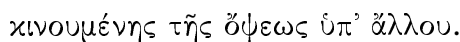

${ }^{5}$ Cambiando lo que hay que cambiar, en la Ética nicomáquea Aristóteles subraya las interferencias pasionales que obstruyen la aprehensión del bien real: "en la

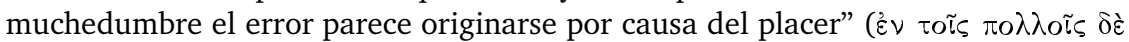

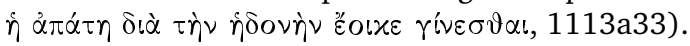

Diánoia, vol. LIV, no. 63 (noviembre 2009). 
más fácilmente en error: los cobardes, infectados por el miedo, ven al enemigo en todas partes". ${ }^{6}$ En esa medida, podría objetarse que Boeri no está autorizado a generalizar las consecuencias anómalas de algunos estados pasionales sobre nuestras percepciones, como si aquéllos fuesen la única fuente del error perceptivo, o éste sólo ocurriese en tales circunstancias. En particular, la experiencia de los sensibles propios no parece igualmente vulnerable a esos influjos emotivos. Con todo, no puede negarse que es el propio Aristóteles quien compara lo que podríamos llamar el error de apreciación moral (o el error en la estimación del valor moral de una acción o pasión) con la incapacidad de practicar ciertas discriminaciones sensoriales básicas. En Ética nicomáquea III 4 (1113a26-29) parangona al incapaz de apreciar lo que por naturaleza

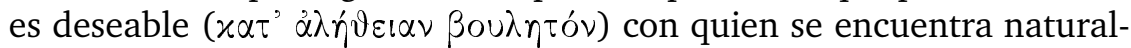
mente indispuesto para apreciar lo dulce y lo amargo, lo pesado y lo liviano, lo saludable y lo nocivo. En cambio, al bueno o al "bien dispuesto" se le aparece lo que es tal como es. Y ello tanto en el dominio de la praxis, como en el de la aprehensión de las contrariedades sensibles básicas. $^{7}$

Es de suponerse, entonces, que los estados o disposiciones anímicos en conformidad con los cuales el agente discierne lo genuinamente apetecible guardan alguna proporción estructural con las disposiciones del cuerpo, que lo habilitan para identificar los rasgos cualitativos del paisaje físico. Por lo demás, en De Anima II 5 (417b16-18) Aristóteles comparó la posesión de habilidades intelectuales, que resultan del aprendizaje, con la posesión de facultades sensoriales, que resultan de

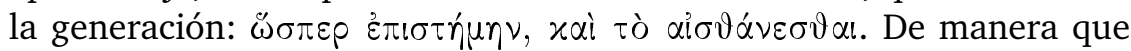
no parece absurdo suponer que la habilidad innata de discriminación

${ }^{6}$ Barnes 1987, p. 55, n. 15. Ejemplos de objetos incidentales de percepción (o sensibles per accidens) son los mencionados en De Anima III 1, 425a24-7; II 6, 418a20-3. La mayor fiabilidad de los sensibles per se ha sido puesta en duda por I. Vasiliou (1996), quien (contra lo afirmado por Barnes y Stopper, véase la nota 1, supra) se esfuerza en mostrar que Aristóteles tuvo escaso interés en hacer frente al desafío escéptico.

${ }^{7}$ También en Metaph. Г 4, 1008b16-20, Aristóteles conecta la aprehensión de nociones prácticas (lo mejor y lo peor, lo conveniente y lo adverso) con la fiabilidad de las discriminaciones sensoriales básicas entre cualidades opuestas dentro del

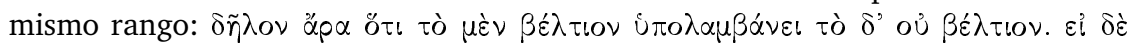

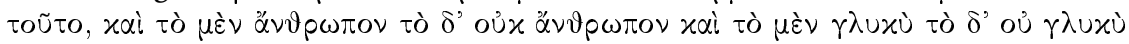
$\alpha \nu \alpha ́ \gamma \chi \eta \dot{u} \pi \circ \lambda \alpha \mu \beta \alpha ́ \nu \varepsilon เ \nu$. Cabe hacer notar que en su discusión de la caracterización

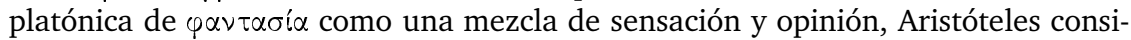
dera tanto cualidades morales ("bueno"), como cualidades sensibles ("blanco"): cfr. De Anima III 3, 428a28-b1. 


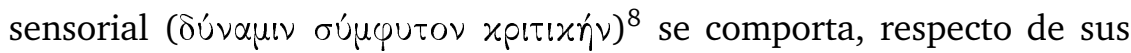
objetos, como las habilidades adquiridas de discriminación moral lo hacen respecto del suyo.

Este paralelismo es instructivo. Lo que parece subyacer a ambos modos de acertar es la presuposición implícita de un criterio natural de rectitud, al que Aristóteles apela tanto en contextos morales como epistémicos. Lo que en definitiva parece dar sustento a las discriminaciones correctas en ambos dominios es un estado saludable del alma ( $\left.\varepsilon^{\xi} \xi \zeta\right)$. El contraste básico opone los bien dispuestos a los "indispuestos", que juzgan sistemáticamente de manera errónea. En uno y otro caso hay una remisión a capacidades innatas o adquiridas de discernimiento, lo que tiende a confirmar la interdependencia entre ambos niveles de discusión. Si en relación con las apreciaciones de lo noble y vergonzoso,

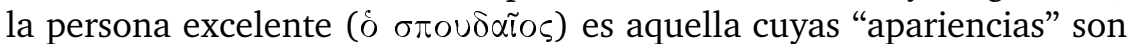
de fiar, porque coinciden con lo que de hecho es noble o vergonzoso, ${ }^{9}$ en relación con los sensibles propios, el organismo sano será a su vez

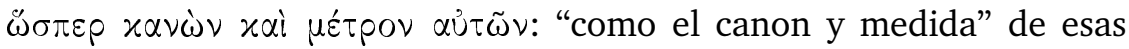
cualidades. Boeri se vale a este fin de un conocido ejemplo:

Que las sensaciones son siempre verdaderas debe significar que, si el órgano del sentido del sujeto percipiente está sano, verá lo que, efectivamente, está viendo - por ejemplo, en un día soleado en un lago de aguas claras verá el remo quebrado-; eso no significa, sin embargo, que el remo esté quebrado o que la proposición "el remo está quebrado" sea verdadera $(A R$, p. 229; las cursivas son mías).

Boeri sugiere, entonces, que el funcionamiento normal del sistema cognitivo de un animal sano provee el paradigma de la experiencia sensorial fiable. Al hacerlo, tiende a atribuir a Aristóteles los rudimentos de una "doctrina del criterio", que empalma punto por punto con su

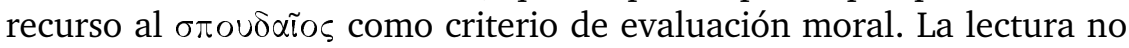
parece antojadiza si se tiene en cuenta el énfasis que Boeri pone en el virtuoso como garante de la veracidad de las apariencias (morales); ese recurso puede transferirse, mutatis mutandis, de contextos prácticos a contextos epistémicos. Escribe Boeri:

[E]l virtuoso aristotélico tiene, como cualquier otro agente racional, apa-

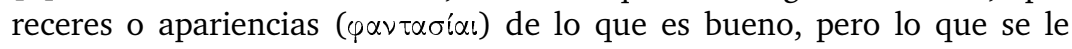

${ }^{8}$ An. Post. II 19, 99b35; cfr. De Motu Animalium, 700b19-21; De Anima III 3, 427a19-21; III 2, 426b8-11. Algunas instancias concretas de discriminación sensorial: II 6, 418a14; II 10, 422a21; III 2, 425b21-2; De Sensu, 436b15.

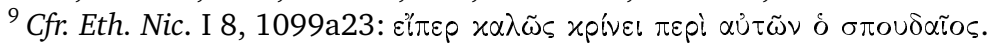

Diánoia, vol. LIV, no. 63 (noviembre 2009). 


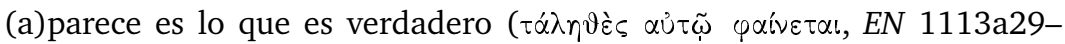
31); y ello es así no sólo por la calidad de sus estados disposicionales, sino también por la calidad de sus capacidades cognitivas. (AR, p. 238)

En otras ocasiones, la formulación de Boeri deja indeciso si las apariencias contrapuestas entre las que el agente discrimina pertenecen al

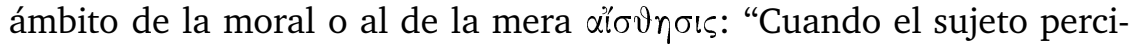
piente dice ' $x$ es $P$ ' y está equivocado o descubre que está en el error, debe presuponer siempre un criterio para distinguir lo verdadero de lo falso" (AR, p. 230).

Ahora bien, si las sensaciones elementales son fiables (e incluso infalibles), ${ }^{10}$ experiencias más complejas, que involucran objetos incidentales de percepción, comprometen el ejercicio coordinado de los dos tipos de capacidades que el $\sigma \pi \circ \cup \delta \alpha \tilde{\imath} о \varsigma$ pone en juego: la receptividad sensible y el arte de la medida, o la capacidad intelectual de distanciamiento. La aptitud de discernir entre lo aparente y lo real se pone a prueba cuando es preciso mantener una creencia a despecho de las apariencias. Aristóteles ilustra ese caso crítico mediante el conocido ejemplo del sol que "aparece" de pequeño diámetro, sin que prestemos nuestro asentimiento a esa impresión. ${ }^{11}$ El pasaje entabla una contraposición tajante: las cosas aparecen de cierta manera, pero cabe creer que son de otra ( $(\alpha i v \varepsilon \tau \alpha \iota \mu \grave{\imath} \nu . . . \pi l \sigma \tau \varepsilon \dot{\varepsilon} \varepsilon \tau \alpha l \delta \varepsilon$ ). De acuerdo con la exégesis de Boeri ( $A R$, pp. 211 y 230), mientras la apariencia potencialmente engañosa no se articule en un juicio descriptivo del estado de cosas que ella presenta, susceptible de verdad o falsedad, no hay todavía una creencia

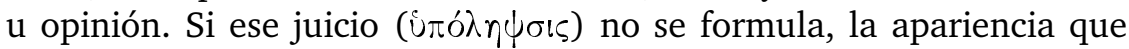
le da sustento es inocua o inofensiva. En términos de Boeri, "en un

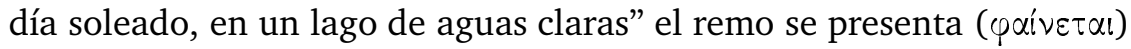
quebrado, aunque el observador no crea que lo esté. Para opinarlo tiene que creerlo; para creerlo, debe persuadirse antes de ello; y para ser

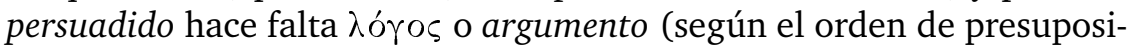
ción entre las actitudes proposicionales, descrito en 428a22-34). Ahora bien, algunos animales tienen apariencias, pero no discurso argumen-

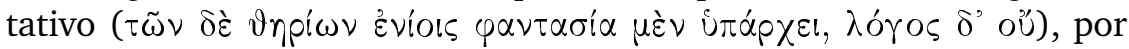
lo cual su relación con las impresiones sensibles no será conflictiva, en

${ }^{10}$ De Anima II 6, 418 a11-16; De Sensu 4, 442b8-10. Aristóteles matiza un tanto estas afirmaciones en De Anima III 3, 428b18-19 (véase la nota 3, supra).

11 De Anima III 3, 428b1-9. Otro lugar en el que Aristóteles recurre al mismo

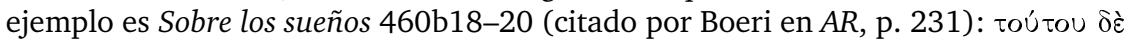

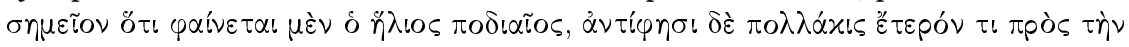
$\propto \nu \tau \alpha \sigma i \alpha \nu$. 
la medida en que no tienen nada que oponer a ellas. Luego, no serán

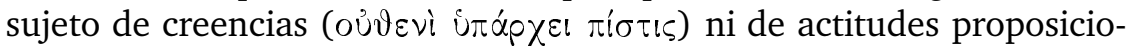
nales complejas frente a lo que les aparece por vía senso-perceptiva, dado que tales actitudes presuponen $\lambda$ óros. El animal se mantiene en la inocencia del aparecer, pues no está en condiciones de formar una opinión (verdadera o falsa) respecto de aquello que se le presenta. Probablemente el énfasis recae aquí en que la posesión de $\lambda$ ó $\gamma$ os permite mediar el mero aparecer y diferir el asentimiento irreflexivo que los animales prestan a "lo que se presenta". El $\lambda o ́ \gamma o \varsigma$ instituye así un hiato entre el mero aparecer y la creencia, al proporcionar un patrón o medida con el que enjuiciar las apariencias. ${ }^{12}$

Lo interesante es que ese patrón rige tanto en las apreciaciones teóricas (v.gr. la estimación del diámetro solar) como prácticas. Es llamativo a este respecto que Marcelo Boeri diseñe su propio experimento mental, estrictamente paralelo al ejemplo astronómico elaborado por Aristóteles para ilustrar el conflicto entre apariencia y creencia, pero traspuesto esta vez a contextos de racionalidad práctica:

[E]n un día de calor un hombre y un buey que ven un espejo de agua pueden encontrar dicho espejo de agua como algo deseable. Pero si el hombre tiene una evidencia mínima [sc., $\pi i \sigma \tau \iota \varsigma]$ de que ese líquido puede estar contaminado, será capaz de demorar la satisfacción de su deseo. ( $A R$, p. 236$)^{13}$

En el ejemplo de Boeri la creencia no acompaña (sino que contraviene) lo aparente. El arte de la medida se sobrepone así al poder de la apariencia, de un modo análogo a lo que ocurría en el ejemplo astronómico, donde una creencia verdadera acerca del diámetro solar (iđó̀ $\alpha \lambda \eta \eta \tilde{\eta})$ lograba neutralizar la $\varphi \alpha \nu \tau \alpha \sigma i \alpha$, o mantenerla a distancia suficiente como para juzgar su concordancia con los hechos. El contraste del Protágoras muestra de este modo un radio de aplicación que cubre por igual lo epistémico y lo práctico. ${ }^{14}$

\footnotetext{
${ }^{12}$ Naturalmente, Aristóteles considera la eventualidad de agentes racionales que renuncian a ejercer sus capacidades de discriminación intelectual y viven por debajo de sus posibilidades cognitivas y morales: cfr. De Anima III 10, 433a10-12.

${ }^{13} C f r$. también $A R$, p. 237: "[el hombre sediento] puede satisfacer su sed si bebe de su botella, que es una fuente de agua confiable [ $\left.\pi_{i} \sigma \tau \iota \varsigma\right]$ ". A juzgar por De Anima III 3, 428a21-4, las bestias no confían (ni desconfían) de las apariencias. Para hacerlo es necesario disponer de algún tipo de razón o argumento, y ello requiere estar situado, en cierto modo, más allá de lo aparente.

${ }^{14}$ Para otro ejemplo moral estructuralmente análogo al ejemplo del diámetro
} 
Boeri concluye que "el entrenamiento adecuado de las capacidades cognoscitivas y, en el plano práctico", de las virtudes y de la prudencia "garantizarán (sic) que los apareceres que el sujeto identifica con el bien coincidan efectivamente con el bien" ( $A R$, p. 238). Lo que parece subyacer, entonces, a su reflexión es la búsqueda de un garante que permita entablar discriminaciones fiables entre nuestras apariencias, cualesquiera que éstas sean; y Boeri encuentra ese garante en el refinamiento de las capacidades cognitivas y de las disposiciones del carácter del agente de praxis. Tal refinamiento se hace necesario porque nuestras apariencias involucran muchas veces objetos incidentales de percepción, respecto de los cuales nuestro aparato cognitivo está lejos de ser infalible. En efecto, buena parte de los contraejemplos que se suele aducir contra la fiabilidad de las senso-percepciones toman pie en la identificación errónea de los sustratos de los sensibles propios: son éstos los que no siempre aparecen como son. Por el contrario, piensa Aristóteles, la aprehensión de las contrariedades cualitativas básicas es prácticamente infalible en las condiciones ambientales apropiadas. La embrionaria atribución de un "criterio de verdad" a Aristóteles parece, pues, bien documentada en este libro.

\section{Una respuesta aristotélica al desafío escéptico}

Esta atribución no es un anacronismo, o constituye a lo sumo un "anacronismo inofensivo" (Barnes 1987). Lo común a todos los estados disposicionales de discernimiento correcto es "el encontrarse bien dispues-

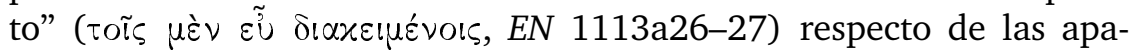
riencias sobre las cuales recae el juicio. En cada uno de estos ámbitos fenoménicos Aristóteles instituye un juez supremo. En lo tocante a las apariencias sensibles inmediatas, todos los animales sanos son buenos jueces, y Aristóteles tiende a localizar el error en alguna ofuscación (temporal o permanente) de nuestro sistema cognitivo, que entorpece el buen ejercicio de esa "capacidad de discriminación innata" entre apariencias elementales (dulce, salado; rojo, verde; agudo, grave; suave, áspero, etc.). ${ }^{15}$ Hay rangos cualitativos en relación con los cuales somos óptimos jueces y a los que tenemos un acceso inmejorable, por hallarnos por naturaleza bien constituidos respecto de esas contrariedades. En ese sentido, el buen funcionamiento de la Qúoıs — amparado solar, cfr. Ética Eudemia 1235b22-29, con la respectiva discusión de Boeri (AR, p. 231).

${ }^{15}$ Para algunas alteraciones orgánicas que impiden temporalmente la correcta discriminación perceptiva, cfr. De Anima II 10, 422b5-10; I 4, 408b19-24. 
en consideraciones teleológicas del tipo "la naturaleza no hace nada en vano"- provee (en contextos epistémicos) la instancia última e inapelable para discernir entre apariencia y realidad. No cabe remontar, por ejemplo, hacia una justificación (trascendental) de esas capacidades que no presuponga su ejercicio. Aristóteles no cree posible suspender momentáneamente el juicio para examinar el alcance y la fiabilidad de nuestros juicios - y eso parece imprimirle un carácter peculiar a su modo de hacer filosofía-.

Como es sabido, en Metafísica $\Gamma 5$ Aristóteles considera la eventualidad, propuesta por Protágoras, de un mundo en el cual la opinión errónea sea la regla, y sólo unos pocos posean una adecuada capacidad de discernimiento entre las cualidades sensibles elementales. En ese universo patológico, lo que es de suyo dulce se mostrará amargo a casi todos; y como es absurdo arbitrar estas cuestiones por recurso a la simple mayoría, Protágoras propone dar por verdaderas todas las apariencias. Es la tesis, ya discutida en el Teeteto,${ }^{16}$ de que las percepciones son infalibles, y lo que aparece amargo a una persona en el instante $t_{1} e s$ amargo sin más - si bien nada lo será incondicionalmente o de suyo, sino sólo para alguien, durante algún instante, en ciertas condiciones, etc.- . Todos los predicados cualitativos se muestran, a la postre, como predicados relacionales encubiertos ${ }^{17}$ que omiten su referencia a las circunstancias de su enunciación sólo por razones de economía expresiva. Al otorgar igual autoridad a todas las apariencias, la tesis de Protágoras impide discriminar entre ellas.

La respuesta que Aristóteles propone en tales casos podría parecer decepcionante. Más allá de la distinción entre el funcionamiento normal y el funcionamiento anómalo de las capacidades cognitivas innatas, Aristóteles no parece interesado en proveer un argumento conclusivo en contra de un desafío escéptico global, que cuestione la veracidad de lo que se le presenta incluso a un animal sano. Sin embargo, Aristóteles parece tener buenas razones para ello. Él piensa que lo mejor que cabe hacer en tales casos no es definir un criterio (distinto de la percepción) que permita satisfacer las demandas escépticas por una discriminación entre lo aparente y lo real. Lo que procede es más bien descartar como poco razonables esas mismas demandas, por provenir de una concepción errónea acerca de lo que constituye (o no) una justificación aceptable. La línea argumentativa (ejecutada en An. Post. I 3) se encamina a

${ }^{16}$ Cfr. Teeteto, 157e-158e; 178b5-9.

${ }^{17}$ Cfr. Teeteto, 160b8-c2. En Metaph. Г 6, 1011a19-20, Aristóteles explicita esta

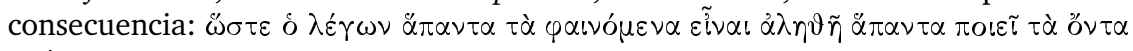

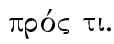

Diánoia, vol. LIV, no. 63 (noviembre 2009). 
mostrar que si de todo hay que dar razón, entonces no es posible dar razón de nada. No cabe demostrar la fiabilidad de nuestras percepciones pues (parece creer Aristóteles) quien supone que sólo es aceptable una justificación demostrativa considerará a la postre inaceptable toda justificación —incluida (paradójicamente) una justificación demostrativa-. En efecto, el argumento diseñado para validar la percepción reposará en principios que deben ser demostrados y éstos a su vez en otros, de tal suerte que la empresa de validación del saber se reanudará a cada paso sin llegar nunca a su término. Para hacer posible la demostración, es preciso afirmar "no sólo que hay ciencia, sino también algún princi-

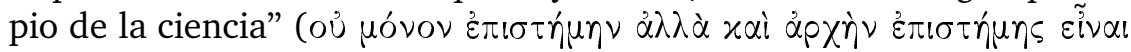
$\tau \iota \nu \alpha$ ), principio cuyo conocimiento es rigurosamente "indemostrable"

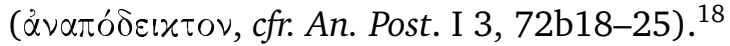

En suma, la respuesta aristotélica al escepticismo radical consiste en una crítica de los estándares de justificación epistémica que subyacen a la demanda escéptica. ${ }^{19}$ De ahí el recurso, a partir de Metafísica $\Gamma 4$, a la "contradicción performativa": ${ }^{20}$ el escéptico profesional conduce su vida práctica con arreglo a una serie de discriminaciones triviales (entre lo dulce y lo amargo, el sueño y la vigilia, la opinión vulgar y la opinión experta) ${ }^{21}$ de las cuales no puede dar razón, porque están presupuestas en todo "dar razón". Se trata de intuiciones cuya justificación es "primitiva" o "básica". Eso no significa que el punto de partida del conocimiento sea inaccesible a un examen racional: respecto de las primeras evidencias, Aristóteles propone "otro tipo de búsqueda" y otro

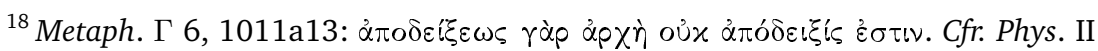
1, 193a4-9. No es posible ofrecer aquí una reconstrucción detallada del modelo aristotélico de saber demostrativo; nos limitamos a indicar sumariamente aquellos rasgos del modelo que son pertinentes para la presente discusión. Para un análisis pormenorizado, cfr. Berti 1965; Bolton 1990; y Mignucci 2007.

${ }^{19}$ Como observa T. Irwin (1988, p. 195): "Aristóteles nota que la posición escéptica colapsará a menos que ellos [sc., los escépticos] logren persuadirnos a nosotros (no escépticos) de aceptar sus demandas como razonables [...]. Si Aristóteles está en lo correcto, nosotros no aceptamos de entrada los estándares escépticos. No esperamos que cada creencia sea justificada en virtud de un principio universal más seguro." En esa medida, el escéptico no puede socavar nuestras intuiciones básicas sin persuadirnos antes de que es razonable aspirar a fundarlas deductivamente.

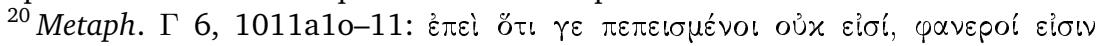

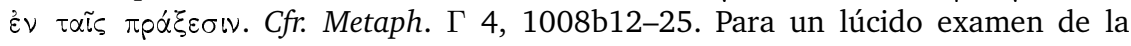
argumentación desarrollada en Metaph. $\Gamma 5$ en conexión con los argumentos de Protágoras, véase Kenny 1967.

${ }^{21}$ Cfr. Metaph. $\Gamma$ 6, 1011a4-6. Para la discriminación entre opiniones desigualmente autorizadas, véase también Teeteto 178b9-d10. 
tipo de hallazgo, ${ }^{22}$ pues tanto el hecho de que son, como su contenido,

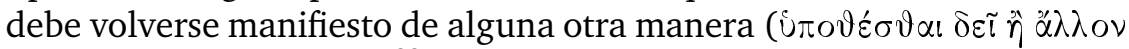

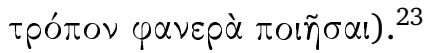

En definitiva, la discriminación entre apariencias contrapuestas no es tan desesperada como el escéptico supone, y parece estar al alcance de cualquiera que ejerza sus facultades sensoriales en condiciones ambientales apropiadas. Aristóteles proporciona algunos indicios del modo en que eso ocurre cuando alude a la autoridad de cada canal perceptivo respecto de su sensible propio; ${ }^{24} \mathrm{y}$, en el caso de los sensibles comunes, a la corrección de los reportes sensoriales confusos mediante la injerencia de algún otro sentido más autorizado. El tratado Sobre los sueños refiere que, al palpar con los dedos entrecruzados una superficie, podemos experimentar la misma sensación que tendríamos al tocar dos objetos discontinuos, de tal manera que lo uno se nos muestra como

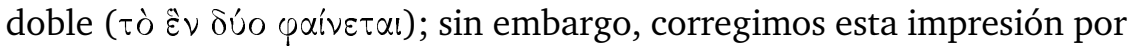
medio de la vista, y no afirmamos que haya allí tantas cosas cuantas

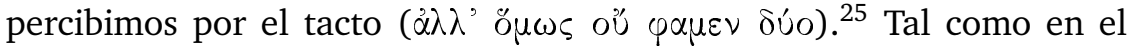
ejemplo del sol que "aparece" de pequeño diámetro, el arte de la medida relativiza el reporte sensorial, impidiendo que éste desencadene inmediatamente un juicio erróneo. De suyo, la apariencia táctil sólo engaña a quien se deja engañar por ella, al formular un juicio precipitado. La estrategia de Aristóteles consiste, entonces, en banalizar la distinción "apariencia-realidad", mostrando que ella permanece a salvo mientras no se intente fundarla del modo apodíctico que el escéptico exige. Más que como una resolución en regla, la respuesta aristotélica puede ser vista como un intento de disolución de la dificultad, al mostrar el modo en que ésta surge a partir de una equivocada idea de la justificación epistémica.

\section{Conclusión}

El hecho de que Aristóteles recurra a una refutación indirecta del escepticismo global por recurso a la "contradicción performativa" parece validar la intuición de Boeri, al mostrar la relevancia de consideraciones pragmáticas en la resolución de controversias teóricas. La correspondencia estructural entre el error cognitivo y el error moral justifica el

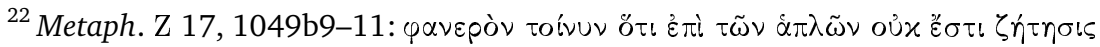

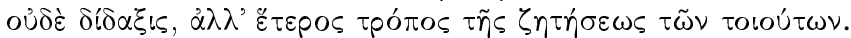

${ }^{23}$ An Post. II 9, 93b23-24.

${ }^{24}$ De Anima III 2, 426b8-12; cfr. II 6, 418a9-16; 418a24-25.

${ }^{25}$ Sobre los sueños, 460b20-27. 
tratamiento conjunto de ambos estados del alma. Ello da pie para entablar una dependencia mutua entre juicios teóricos y prácticos. En el plano estrictamente teórico, ciertas apariencias elementales (los "sensibles propios") operan como medida última del juicio; en el plano práctico, es el juicio el que opera como medida de las apariencias complejas, revelando a algunas de ellas como engañosas. ${ }^{26}$ En definitiva, la capacidad de discriminación racional entre apariencias contrapuestas no puede justificarse deductivamente, pues toda justificación presupone la veracidad de algunas apariencias.

Hubiese sido deseable que Marcelo Boeri fuese un tanto más explícito al perfilar cuál es ese criterio que Aristóteles parece "haber visualizado [y] del cual nosotros todavía disponemos cuando hacemos la distinción apariencia-realidad" ( $A R$, p. 230). La discusión desplegada en la segunda parte de esta nota procuró rastrear algunos indicios textuales que avalan la intuición central de Boeri, en cuanto a la presencia subyacente de un criterio de rectitud, aplicable tanto a las apariencias cognitivas como a aquellas que inciden en la deliberación práctica. Si nuestra interpretación es correcta, la respuesta de Boeri consiste en subrayar la fiabilidad de las habilidades innatas de discriminación perceptiva, insistiendo a la vez en la relevancia de las habilidades adquiridas de distanciamiento moral.*

\section{BIBLIOGRAFÍA}

Barnes, J., 1987, "An Aristotelian Way with Scepticism", en M. Matthen (comp.), Aristotle Today. Essays on Aristotle's Ideal of Science, Academic Printing and Publishing, Alberta, pp. 51-76.

Berti, E., 1965, L'Unità del sapere in Aristotele, Cedam, Padua.

Boeri, M., 2007, Apariencia y realidad en el pensamiento griego, Colihue, Buenos Aires.

Bolton, R., 1990, "The Epistemological Basis of Aristotelian Dialectic", en

D. Devereux y P. Pellegrin (comps.), Biologie, Logique et Métaphysique chez Aristote, CNRs, París, pp. 185-236.

${ }^{26}$ También la evaluación racional de las apariencias se ejerce respecto de aquellas que no tienen relevancia práctica ni mueven al agente a obrar $(v . g r$. "el sol tiene siete pies de diámetro"). Sin embargo, la corrección del reporte sensorial por recurso a una creencia sólo puede tener lugar en el ámbito de los objetos incidentales (y no en el de los objetos elementales) de percepción. Respecto de estos últimos, cada canal perceptivo es soberano.

${ }^{*}$ El presente artículo fue redactado en el marco de un proyecto de investigación en torno de la psicología de Aristóteles, financiado por Fondecyt (Chile) (Proyecto no. 3085014). Agradezco las sugerencias de los árbitros anónimos de Diánoia, que me permitieron precisar algunos argumentos y mejorar su formulación. 
Irwin, T., 1988, Aristotle's First Principles, Clarendon, Oxford.

Kenny, A., 1967, "The Argument from Illusion in Aristotle's Metaphysics ( $\Gamma$, 1009-1010)", Mind, vol. 76, no. 302, pp. 184-197.

Mignucci, M., 2007, Aristotele. Analitici Secondi, Laterza, Roma/Bari.

Stopper, M.R., 1983, "Schizzi Pirroniani", Phronesis , vol. 28, no. 3, pp. 265297.

Vasiliou, I., 1996, "Perception, Knowledge, and the Sceptic in Aristotle", Oxford Studies in Ancient Philosophy, vol. 14, pp. 83-131.

Recibido el 2 de febrero de 2009; aceptado el 8 de septiembre de 2009. 